\title{
Phylogeny and Biogeography of Serolid Isopods (Crustacea, Isopoda, Serolidae) and the Use of Ribosomal Expansion Segments in Molecular Systematics
}

\author{
Christoph Held \\ Lehrstuhl für Spezielle Zoologie, Gebäude ND05-755, Ruhr-Universität Bochum, D-44780 Bochum, Germany
}

Received December 4, 1998; revised October 8, 1999

In this study, a molecular phylogenetic hypothesis for 16 species of serolid isopods (Crustacea, I sopoda, Serolidae) from Antarctic waters, the deep sea, South America, and Australia is presented. The genes used are a 500-bp fragment of the mitochondrial LSU rRNA gene and a 700-bp fragment located in the variable region V4 of the nuclear SSU rRNA gene. The species composition and monophyly of morphologically defined genera of which several members were available are confirmed by the molecular data (Ceratoserolis, Spinoserolis, and Cuspidoserolis). The molecular data also support the redefinition of Frontoserolis s.l. and Serolel la and the erection of the new genera Septemserolis and Paraserolis, as proposed by Wägele. The relationship among several genera is resolved differently in the molecular hypothesis than in the two existing morphological hypotheses, however. The molecular phylogeny may have important consequences for understanding the biogeography of the Serolidae, indicating that all Antarctic species in this study form a monophyletic group which has probably derived from species with closest extant relatives in South America. All 3 species included in this study living today in deep waters ( $>2000 \mathrm{~m}$ ) of the Southern Ocean are most closely related to species living on the Antarctic shelf, so that parallel colonization of the deep sea by way of polar submergence can be reconstructed. In this study, a V4 expansion segment is reported which exceeds the longest crustacean sequences known until now by more than $270 \mathrm{bp}$. Although the V4 expansion segment has proven useful for phylogenetic purposes in this study, there is circumstantial evidence that its mechanism of evolution may depend not only on inheritance of single-site substitutions, making its routine use in phylogenetic studies potentially dangerous. 2000 Academic Press

Key Words: molecular systemati cs; nuclear small subunit ribosomal RNA gene; expansion segment V4; mitochondrial large ribosomal subunit gene; Serolidae; deep sea; biogeography.

\section{INTRODUCTION}

The Serolidae are a family of benthic marine isopods. There are currently 86 recognized species which are distributed predominantly on the continental shelves of the southern hemisphere (Antarctica, South America, Australia), although some species have also invaded the deep sea or extended their range into the northern hemisphere (Poore and Brandt, 1997; Wägele, 1994). After a period of time during which the growing number of described species had been collected in a single genus Serol is Leach, 1818, several genera were erected to structure the rich morphological variation found in this family. Recently Brandt $(1988,1991)$ and Wägele (1994) revised the family at the genus level to identify monophyletic groups but came to different conclusions in their reconstructed phylogenies (Fig. 1). Examination of large numbers of specimens over relatively broad geographical ranges, furthermore, reveals a striking amount of intraspecific morphological variation which casts doubt on the taxonomic usefulness of several morphological features and leaves some taxonomic issues controversially discussed (Holdich and Harrison, 1980; Pooreand Brandt, 1997; Wägele, 1986).

In addition to presenting different views on the phylogeny, the two hypotheses cometo largely incompatible conclusions with regard to the historical biogeography of the group. Neither hypothesis allows a simple explanation of horizontal and vertical distribution patterns within the family.

In this study a first molecular phylogenetic hypothesis for the family Serolidae is presented. The aim of this study is to address open questions concerning its phylogeny and to attempt an explanation of the biogeographical patterns found among extant members of the family. It is not intended to give a full review of the taxonomy of the family at this time. This is particularly so because specimens in museum collections cannot routinely be used for molecular work due to fixation of material in formalin. The number of species at this stage representing the Serolidae is therefore limited to 16 species from 12 genera from Antarctica, South 


\section{Brandt (1991)}

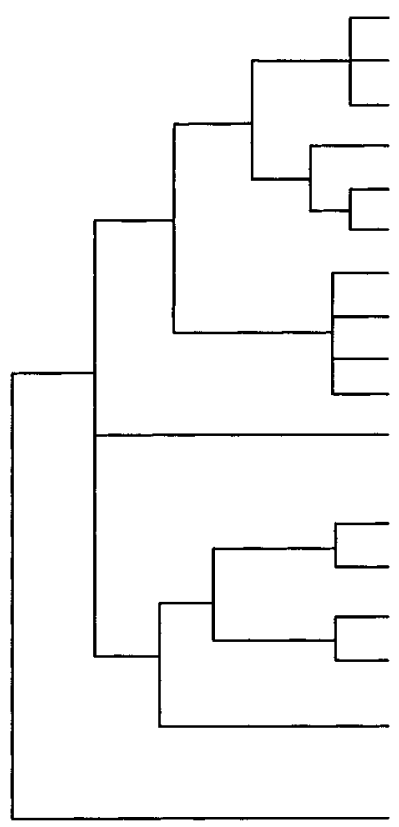

Wägele (1994)

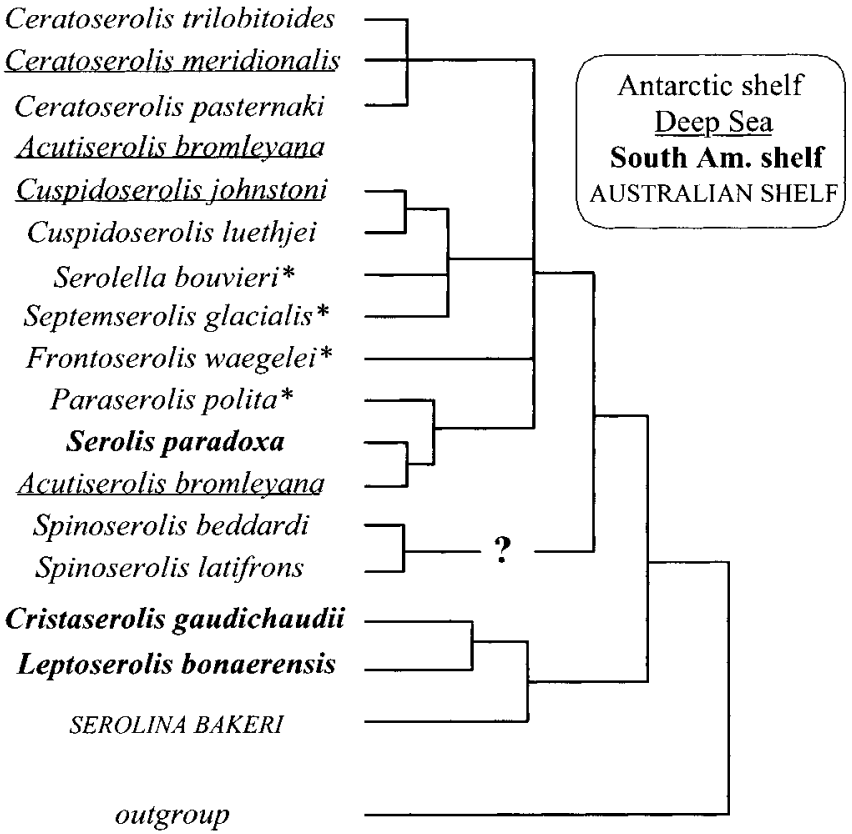

FIG. 1. Phylogenetic hypotheses of Serolidae at the genus level, modified after studies by Brandt (1991) and Wägele (1994), which are based on different sets of morphological characters. The four species marked with an asterisk $(*)$ were placed within the genus Frontoserolis prior to Wägele (1994) and hence are unresolved in the left tree (see Discussion). Only a subset of species included in the studies by Brandt and Wägele is shown here to facilitate comparison with the results of this study. The deep-sea species A. bromleyana is included twice due to different positions in the trees.

America, and Australia; 3 isopod species from other families have been included in this study as outgroup species (Table 1 ).

Of the two genes applied in this study the mitochondrial LSU gene (16S rDNA) has been used over a wide range of taxa and timescales in many studies (Schubart et al., 2000). The V4 nuclear SSU ribosomal expansion segment has been described for a limited number of Crustaceans (Creaseand Col bourne, 1998) and is rarely used for phylogenetic purposes in Crustaceans. The complete 18S rDNA normally varies between approx 1800 and 2000 bp in Crustacea; however, in most Peracarida and one cladoceran sequence, elongations up to 3400 bp have been found, most of which are located in four variable regi ons (Spears, unpubl.; Crease and Colbourne, 1998). In this study a V4 segment is reported that exceeds the longest crustacean sequences known until now by more than 270 nucleotides. Its utility for molecular taxonomical studies will be briefly discussed.

\section{MATERIAL AND METHODS}

\section{Origin of Material and Outgroup Choice}

Antarctic isopod material was collected during two cruises with the research vessel "Polarstern" to the Eastern Weddell Sea (ANT XIII/3) and to the Antarctic
Peninsula (ANT XIV/2). Material was sorted out by hand from trawled gear (Agassiz' trawl, bottom trawl, mini dredge; occasionally also from epibenthic sledge, benthopelagic net, and rectangular midwater trawl) and preserved in prechilled $80 \%$ ethanol. Samples were obtained from water depths between 87 and $3720 \mathrm{~m}$. Subantarctic, Australian, and South American species were collected by scuba diving or by collecting in the tidal zone (Spinoserolis latifrons, Serol ina bakeri, Cristaserolis gaudichaudii, Leptoserol is bonaerensis, Serolis paradoxa, and Plakarthrium punctatissimum). Until further usage, samples were stored in ethanol at low temperatures $\left(-30\right.$ to $\left.4^{\circ} \mathrm{C}\right)$. Species names, sampling locality, EMBL accession number, and collection numbers in the Museum für Naturkunde (Berlin, Germany) are given in Table 1. Plakarthrium punctatissimum (Isopoda, Plakarthriidae), one of the closest living relatives of the Serolidae (Wägele, 1989), Glyptonotus antarcticus (I sopoda, Valvifera, Chaetiliidae), and Antarcturus spinacoronatus (I sopoda, Valvifera, Arcturidae) were chosen as members of the outgroup. Only a subset of these were eventually available for either gene, as discussed below. The Acutiserolis material from the deep sea was identified as bromleyana with difficulty, since it differs from the description in a number of respects. The author agrees with Poore and Brandt (1997) that the genus is in need of revision. 
TABLE 1

Taxa, Collection Localities, and Availability of Sequences and Specimens of Isopods Used in This Study

\begin{tabular}{|c|c|c|c|c|}
\hline Taxon & Loc. & $\begin{array}{l}\text { Sequence acc. no. } \\
\text { (mt LSU) }\end{array}$ & $\begin{array}{l}\text { Sequence acc. no. } \\
\text { (nSSU) }\end{array}$ & $\begin{array}{l}\text { ZMB collection } \\
\text { number }\end{array}$ \\
\hline Ceratoserolis Brandt, 1988 & $*$ & & $*$ & $*$ \\
\hline Ceratoserolis trilobitoides (Eights, 1833) & EWS & AJ 269799 & AJ 269824 & 27287 \\
\hline Ceratoserol is meridional is (Vanhöffen, 1914) & EWS & A] 269800 & AJ 269825 & 27288 \\
\hline Ceratoserolis pasternaki (Kussakin, 1967) & EWS & Aj 269801 & AJ 269826 & 27289 \\
\hline Cuspidoserolis Brandt, 1988 & $*$ & & $*$ & * \\
\hline Cuspi doserol is luethje (Wägele, 1986) & EWS & AJ 269802 & AJ 269819 & 27290 \\
\hline Cuspidoserolis johnstoni (Hale, 1952) & EWS & AJ 269803 & Aj 269817 & 27291 \\
\hline Acutiserolis Brandt, 1988 & $*$ & & $*$ & $*$ \\
\hline Acutiserol is broml eyana (Willemoes-Suhm, 1874) & DP & AJ 269805 & AJ 269818 & 27292 \\
\hline Serolella Pfeffer, 1891 & $*$ & & & $*$ \\
\hline Serolella bouvieri (Richardson, 1906) & EWS & AJ 269804 & AJ 269820 & 27293 \\
\hline Septemserolis Wägele, 1994 & $*$ & & * & $*$ \\
\hline Septemserol is glacial is (Tattersall, 1921) & EWS & AJ 269806 & AJ 269821 & 27294 \\
\hline Frontoserolis Brandt, 1991 & & & $*$ & $*$ \\
\hline Frontoserolis waegel ei (Brandt, 1988) & SSI & AJ 269807 & AJ 269822 & 27295 \\
\hline Paraserolis Wägele, 1994 & $*$ & & $*$ & * \\
\hline Paraserolis polita (Pfeffer, 1887) & SSI & AJ 269808 & AJ 269823 & 27296 \\
\hline Serol is Leach, 1818 & $*$ & & * & $*$ \\
\hline Serolis paradoxa (Fabricius, 1775) & MS & AJ 269811 & AJ 269827 & 27297 \\
\hline Leptoserolis Brandt, 1988 & $*$ & & $*$ & $*$ \\
\hline Leptoserolis bonaerensis (Bastida \& Torti, 1967) & ARG & AJ 269812 & $\mathrm{n} / \mathrm{a}$ & 27305 \\
\hline Cristaserolis Brandt, 1988 & $*$ & & $*$ & $*$ \\
\hline Cristaserolis gaudichaudii (Audouin \& Edwards, 1840) & MS & AJ 269813 & AJ 269828 & 27298 \\
\hline Spinoserolis Brandt, 1988 & $*$ & & $*$ & $*$ \\
\hline Spinoserolis beddardi (Calman, 1920) & SSI & AJ 269810 & $\mathrm{n} / \mathrm{a}$ & 27300 \\
\hline Spinoserol is latifrons (White, 1847) & Kerg & A) 269809 & $\mathrm{n} / \mathrm{a}$ & 27299 \\
\hline Serolina Poore, 1987 & $*$ & & $*$ & $*$ \\
\hline Serolina bakeri (Chilton, 1917) & TM & AJ 269814 & $\mathrm{n} / \mathrm{a}$ & 27301 \\
\hline Plakarthriidae Richardson, 1904 & $*$ & & $*$ & $*$ \\
\hline Plakarthrium punctatissimum (Pfeffer, 1887) & SSI & AJ 269815 & $\mathrm{n} / \mathrm{a}$ & $27302 \S$ \\
\hline Chaetiliidae Dana, 1853 & $*$ & & $*$ & $*$ \\
\hline Glyptonotus antarcticus (Eights, 1853) & EWS & AJ 269816 & $\mathrm{n} / \mathrm{a}$ & 27303 \\
\hline Arcturidae White, 1850 & $*$ & & $*$ & $*$ \\
\hline Antarcturus spinacoronatus (Schultz, 1978) & EWS & $\mathrm{n} / \mathrm{a}$ & $\mathrm{n} / \mathrm{a}$ & 27304 \\
\hline
\end{tabular}

Note EWS, eastern Weddell Sea around Kapp Norvegia; SSI, South Shetland Islands; DP, Drake Passage; MS, Magellan Strait; Kerg, Kerguelen Islands (shallow subtidal); ARG, Argentina (shallow subtidal); ARG, Argentina (shallow subtidal); TM, Tasmania. Specimens have been deposited at the Museum für Naturkunde in Berlin (ZMB, Germany).

$\S$ Whole specimen has been used for DNA extraction; a specimen from the same collection locality has been deposited instead. Sequence accession numbers: AJ 2697799-AJ 2697828.

Wägele (1994) lists Serolis glacialis as species incertae sedis. However, this species is morphologically so similar to Septemserolis nobilis (Brandt, 1988) that it is justified to include it in this genus until its status is clarified.

\section{Molecular Work}

Total DNA was extracted from muscle tissue samples or individual legs of single specimens using one of the two methods mentioned bel ow. Both recipes have been modified to work with serolid isopods.

The DTAB/CTAB extraction protocol modified after Gustincich et al. (1991) worked well when small amounts of tissue were incubated in large buffer volumes (2-ml Eppendorf tubes) for several hours in a shaking water bath. Alternatively, a spin column extraction with commercially available columns was carried out following the recommendations of the manufacturer (Qiagen). Whereas the incubation time did not seem to influence the outcome significantly, it was critical to keep the amount of tissueas small as possible and to run multiple parallel extractions. Both recipes sometimes yielded no detectable DNA on an agarose gel, although they successfully amplified during PCR. However, increasing the amount of tissue per extraction frequently resulted in unsuccessful PCR runs, indicating that unidentified inhibitors of the PCR copurified with the DNA during the extraction process.

PCRs were carried out in $50-\mu l$ volumes (2 units Qiagen Taq polymerase, $5 \mu \mathrm{l} 10 \times$ PCR buffer, $10 \mu \mathrm{l}$ Q-buffer, $5 \mu \mathrm{l}$ dNTPs, 0.5-1.5 $\mu$ l DNA template, filled to $50 \mu \mathrm{l}$ with sterile $\mathrm{H}_{2} \mathrm{O}$ ). All amplification reactions were carried out in a Perkin-Elmer thermal cycler Model 
2400 or a Techne Progene cycler, with cycle sequencing reactions in the Techne cycler exclusively.

Mitochondrial LargeSubunit Ribosomal RNA Gene (16S rDNA)

Individual DNA was amplified using the widely applicable primers 16Sar 5'-CGCCTGTTTATCAAAAACAT-3' and 16Sbr 5'-CCGGTCTGAACTCAGATCACGT-3' (Palumbi et al., 1991), resulting in a product of approximately $490 \mathrm{bp}$ in length (Table 2). The amplification protocol was $5 \mathrm{~min}$ at $94^{\circ} \mathrm{C}$ for initial denaturing, 35 cycles of $45 \mathrm{~s}$ at $94^{\circ} \mathrm{C}, 45 \mathrm{~s}$ at $52^{\circ} \mathrm{C}$, and 1 min $20 \mathrm{~s}$ at $72^{\circ} \mathrm{C}$, followed by $7 \mathrm{~min}$ for final extension. Nudear Small Subunit Ribosomal RNA Gene(18S rDNA)

Primers 18A1 5'-CCTA(TC)CTGGTTGATCCTGCCAGT-3' and 1155R 5'-CCGTCAATTCCTTTAAGTTTCAG-3' were used for amplification (Dreyer, unpubl.). On the basis of the $18 \mathrm{~S}$ sequences from serolid isopods obtained by sequencing the above PCR products, an additional pair of internal primers, Sbeb27P 5'AGTTGGATTTCTCTTTCGGACC-3' and Sbeb755N 5'TTTATCATTACCTCGGGTTCAG-3', was designed and used successfully in the course of this study. The amplification protocol was $5 \mathrm{~min}$ at $94^{\circ} \mathrm{C}$ for initial denaturing, 36 cycles of $94^{\circ} \mathrm{C}, 48^{\circ} \mathrm{C}$, and $72^{\circ} \mathrm{C}$, followed by $7 \mathrm{~min}$ at $72^{\circ} \mathrm{C}$ for final extension.

\section{DNA Sequencing}

PCR products were purified using commercially available spin columns (Qiagen). Purity and amount of

\section{TABLE 2}

\section{Length of Gene Regions (in bp) per Species Prior to} Removal of Positions

\begin{tabular}{lcc}
\hline \multicolumn{1}{c}{ OTU } & $16 \mathrm{~S}$ & $18 \mathrm{~S}$ \\
\hline Ceratoserolis trilobitoides & 484 & 671 \\
Ceratoserolis meridional is & 480 & 670 \\
Ceratoserolis pastemaki & 486 & 671 \\
Cuspidoserolis luethjei & 488 & 699 \\
Cuspidoserolis johnstoni & 486 & 700 \\
Acutiserolis bromleyana & 489 & 699 \\
Serolella bouvieri & 489 & 698 \\
Septemserolis glacialis & 488 & 700 \\
Frontoserolis waegelei & 489 & 699 \\
Paraserolis polita & 492 & 701 \\
Spinoserolis latifrons & 488 & $765^{*}$ \\
Spinoserolis beddardi & 488 & $765^{*}$ \\
Serolis paradoxa & 487 & 673 \\
Leptoserolis bonaerensis & 488 & - \\
Cristaserol is gaudichaudii & 491 & 690 \\
Serolina bakeri & 494 & $735^{*}$ \\
Glyptonotus antarcticus & 482 & $660^{*}$ \\
Plakarthrium punctatissimum & 492 & - \\
Antarcturus spinacoronatus & - & $476^{*}$ \\
min-max sequence length & $480-494$ & $476-765$ \\
& & $(670-701)$ \\
\hline
\end{tabular}

\footnotetext{
* Sequence excluded from analysis due to alignment difficulties.
} Numbers in parentheses based on included sequences only.
TABLE 3

Length of Used V4 Region of the Nuclear SSU rRNA Gene in Selected Crustaceans (Helix E 23_1, E 23_2, and E23_5)

Species Length of fragment (bp)

$\begin{array}{ll}\text { Astacus astacus } & 113 \\ \text { Artemia salina } & 104 \\ \text { Daphnia pulex } & 257 \\ \text { Antarcturus spinacoronatus } & 338 \\ \text { Glyptonotus antarcticus } & 527 \\ \text { Ceratoserolis trilobitoides } & 535\end{array}$

Note. Origin of species 1-3 see text, species 4-6 this study.

recovered PCR products were estimated on an ethidium bromide-stained $0.8 \%$ agarose gel; $0.5-4 \mu$ l of purified PCR product were used for dideoxy cycle sequencing using the manufacturer's protocols (Amersham). The reaction mix was reduced to $13 \mu \mathrm{l}$ in volume and overlaid with two drops of light mineral oil. The cycle sequencing amplification protocol was $94^{\circ} \mathrm{C}$ for $2 \mathrm{~min}$ for initial denaturing and $30 \mathrm{cycles}$ of $94^{\circ} \mathrm{C}$ for $25 \mathrm{~s}$, $48^{\circ} \mathrm{C}$ for $25 \mathrm{~s}$, and $70^{\circ} \mathrm{C}$ for $35 \mathrm{~s}$. F or sequencing the $16 \mathrm{~S}$ amplification product, fluorescently labeled primers with the same sequence as for amplification were used and for the $18 \mathrm{~S}$ amplification product, another set of fluorescently labeled primers was designed from isopod and amphipod sequences (Dreyer and Englisch, unpubl.): 700F seq 5'-GTCTGGTGCCAGCAGCCGCG-3', 600F seq 5' -CGTATATTAAAGTTG(CT)TGC-3', 400F seq 5'-ACGGGTAACGGGGAATCAGGG-3', and 1000Rseq 5'-GAACTAGGGCGGTATCTGATCG-3'. 18S rDNA PCR products which had been amplified with primers Sbeb27P and Sbeb27N were sequenced with fluorescently labeled primers with the same sequence as for amplification. In some cases, amplification of the nuclear gene resulted in more than one amplification product. In this case the band with the expected increased length (see Table 3) was excised from the gel, purified, and cloned using standard protocols; 0.5-1.5 $\mu \mathrm{l}$ of the cycle sequencing reaction was loaded onto an automated sequencer (Li-Cor) and sequenced. Gels were proofread using the image analysis software of the automated sequencer.

\section{Sequence Alignment and Phylogenetic Analysis}

Contigs of the gene regions were assembled using the DNAsis software package (Hitachi Co., Ltd.) and individual contig sequences were aligned with ClustalX (Thompson et al., 1997) using the default parameters. The alignments were further improved manually by identifying secondary structure elements of the homologous molecules in Drosophila melanogaster (mitochondrial ribosomal LSU, Accession No. X53506; Gutell et al., 1993) and Astacus astacus (nuclear ribosomal SSU, Accession No. U33181; Van de Peer et al., 1999) using 
the editing program Genedoc V2.5 (Nicholas and Nicholas, 1997). Unexcluded sequences and positions in the datamatrix (see below) were treated as single unorder ed characters; gaps were treated as missing information. Phylogenetic trees were inferred using maximumparsimony (MP) and maximum-likelihood (ML).

In MP reconstructions, transitions were weighted equally (schemeTV1) relative to transversions or downweighted by factors of two or three (schemes TV2 and TV3). Bremer support was calculated by running the programAutodecay 4.0 (Eriksson, 1998) on the shortest tree or the strict consensus of the shortest trees of the separate and combined datasets. Confidence estimates of nodes in MP analysis were obtained by bootstrapping the data matrices with random addition of taxa.

To ensure the choice of a proper model of sequence evolution for ML analysis, a likelihood-ratio test (LRT) was carried out as implemented in model test 2.0 (Posada and Crandall, 1998). ML trees were then constructed using the model determined by the LRT. Sequence evolution parameters were either taken directly from modeltest 2.0 or estimated from within Puzzle 4.02 (Strimmer and von Haeseler, 1996), which were generally in close agreement with the parameter estimates from modeltest.

To clarify the monophyly of the genus Cuspi doserol is, the datamatrix was searched for positions which support either of the two topologies for group I produced by ML and MP methods (see Fig. 5). In short, molecular synapomorphies can be expected to uniquely identify the monophylum whose last common ancestor developed this evolutionary novelty (symmetrical split supporting position, SSSP) or subsequent events can have degraded this signal to some degree in the outgroup, ingroup, or both (asymmetrical and noisy split supporting positions, ASSP, ASSP $+\mathrm{N}$ ). For a more detailed explanation of this method, see Schulenburg et al. (1999) and Wägele (1998). The ingroup of the MP scenario included the two Cuspidoserol is species in this study; the ingroup of the ML scenario comprised C. Iuethjei, A. broml eyana, and S. bouvieri (see Fig. 3) or, alternatively, C. Iuethje and A. broml eyana (see Fig. 5). The noise parameters were varied between 25 and $45 \%$ in the outgroup. Due to the small number of ingroup species, only SSSPs and ASSPs were considered (i.e., positions which did not show heterogeneity within the ingroup).

An incongruence length difference test (ILD test) after Farris et al. (1994), as implemented in the partition homogeneity test in PAUP* (Swofford, 1998), was carried out to justify the combination of the datasets from thetwo genes. For this step, all unvaried positions were excluded from the analysis (Cunningham, 1997).

\section{RESULTS}

The sequences have been deposited at the EMBL database; the specimens, unless destroyed during DN A extraction, have been deposited at the Museum für Naturkunde in Berlin, Germany (Table 1).

\section{Mitochondrial LargeRibosomal Subunit RNA Gene}

The secondary structure of the mitochondrial large subunit ribosomal gene (16S) was in close agreement with the model proposed for Drosophila melanogaster (Gutell et al., 1993). Only stems and loops corresponding to bases 911 to 964 in Drosophila could not be identified within the isopod sequences, which were highly variable in this region. This region, measuring approximately 50 bases in the isopod species in this study, was therefore excluded from the analysis of the 165 dataset, as were the first 16 bases after primer 16Sar, whose alignment strongly depended upon gap cost parameters and which could not be unambiguously aligned upon secondary structure considerations. Of the remaining 453 aligned nucleotide sites, 249 are variable and 180 are potentially parsimony informative. The fragment is AT rich with an average base frequency of $\mathrm{pi}(\mathrm{A})=33.1 \%$, $\mathrm{pi}(\mathrm{C})=16.3 \%$, pi $(\mathrm{G})=$ $16.1 \%$, and pi $(T)=34.5 \%$ and no significant evidence of base frequency heterogeneity among taxa $\left(\chi^{2}=66.24\right.$; $P>0.05)$. Length variation in ingroup and outgroup is moderate, with $433 \mathrm{bp}$ minimal and 441 bp maximal length.

The number of observed substitutions increases almost linearly with evolutionary distance in a pairwise sequence comparison using the GTR model and the same parameters as for phylogenetic tree estimation (Fig. 2). Only sequence comparisons involving the outgroup species show less transitions than expected from a strictly linear increase, indicating beginning saturation. This most likely accounts for stronger bootstrap support when transitions are downweighted during analysis (scheme TV2); however, the effect is weak and omission of outgroup sequences produces an identical tree for the remaining sequences (data not shown). It can therefore be concluded that the phylogenetic analysis is not misled by an excessive amount of multiple substitutions which may otherwise degrade the phylogenetic signal in the data.

The hierarchical likelihood-ratio test suggests a general time reversible model with gamma-distributed rates and a number of invariable sites (Fig. 3). The monophyly of serolids is well supported in the ML tree. The Australian species branches off first, followed by the three South American species. The branching order within the South American species suggests that they are paraphyletic with respect to the Antarctic species. All Antarctic shelf and deep-sea species cluster together with a pronounced division into two groups of taxa. One comprises the genus Ceratoserol is; the other comprises seven Antarctic species and will be called group I for simplicity in the following. 

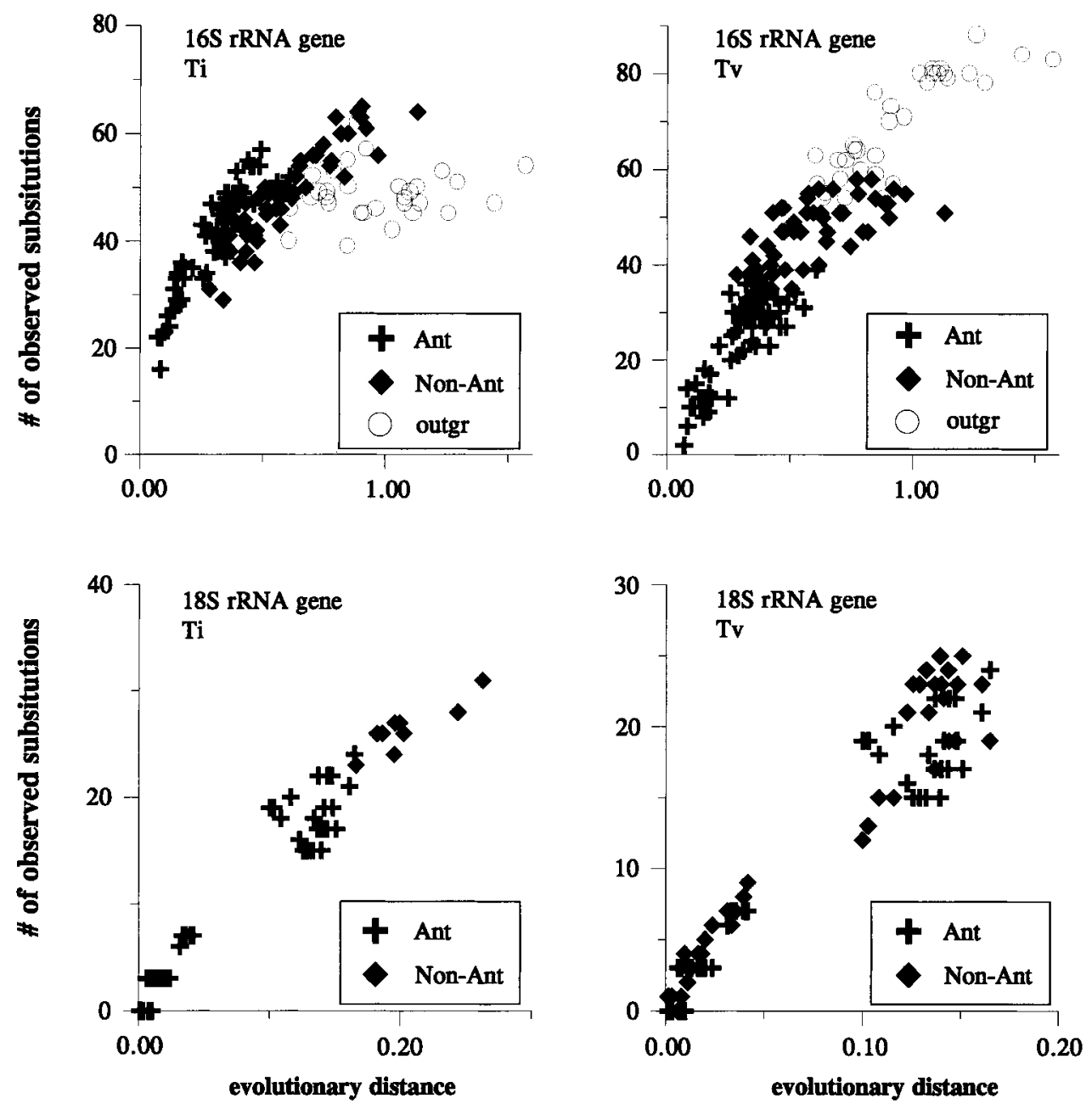

FIG. 2. Saturation plots of the mitochondrial LSU gene (16S) and the nuclear SSU gene (18S) of the serolid isopods in this study. The evolutionary distances were measured using the same models of sequence evolution as for estimating the trees (GTR + I + G and HKY + G). Ti, transition; Tv, transversion; outgr, outgroup species involved; Ant, Antarctic species; NonAnt, South American and Australian species involved.

There are two equally most-parsimonious trees when transitions and transversions are weighted equally (length 745 steps, $\mathrm{Cl}=0.529, \mathrm{RI}=0.490, \mathrm{RC}=0.259$ ). They differ from the ML tree in having a lower resolution toward the base of the tree, but otherwise they are compatible with the ML tree. The affiliation of the Antarctic genus Spinoserol is to either group is not well resolved; it groups with Ceratoserolis in the two shortest trees but this node collapses in trees only 1 step longer. The two shortest trees differ in the position of Acutiserol is, which is a sister group either to Cuspidose rolis or to Serolella. The only incompatibility between the ML and the MP trees is that the genus Cuspidoserolis is a well-supported monophylum in the MP tree. Different weighting schemes for transition and transversion substitutions (TV2: transversions have a weight of two relative to transitions; TV3: transversions have a weight of three) result in minor changes of the topologies of the shortest trees but the topology of the consensus tree (Fig. 3) is not affected by downweighting transitions. The inconsistency between $\mathrm{ML}$ and $\mathrm{MP}$ trees is discussed bel ow.

\section{Nuclear Small Subunit Ribosomal Gene}

Secondary structure alignment for the nuclear small subunit ribosomal gene (18S) is more problematic. The amplified region comprises the nucl eotides homol ogous to the helices E23_1, E23_2, and E23_5 in the secondary structure model for A-stacus astacus proposed by Van de Peer et al. (1999). This region is part of the highly variable region V4, which is subject to extensive variation and length differences among taxa (Crease and Colbourne, 1998; Hancock and Vogler, 1998). For the region treated in this study, length differences in excess of 100 nucl eotides have been reported for Crustacea (see Crease and Colbourne (1998) and references 


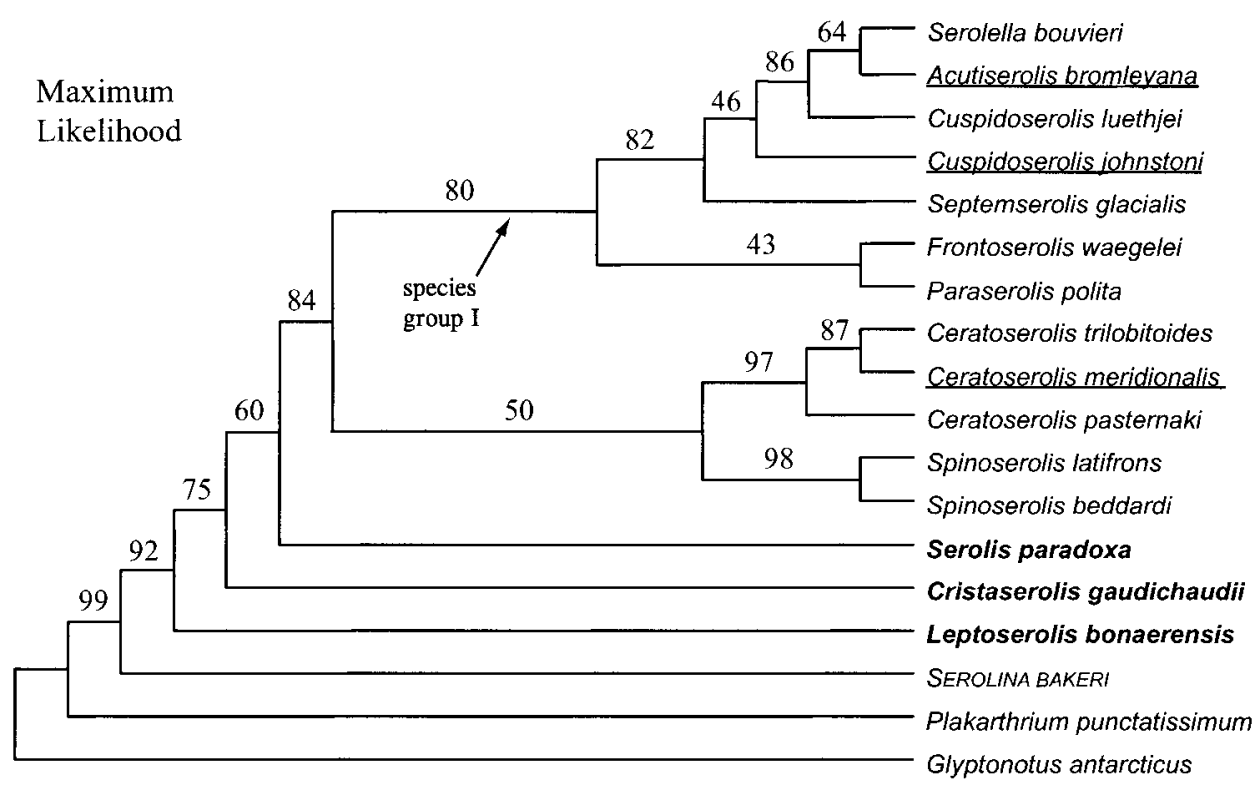

FIG. 3. Phylogenetic tree based on the $3^{\prime}$-terminus of the mitochondrial large subunit rRNA gene (16S) of 16 species of serolid isopods. The model of sequence evolution was chosen by a hierarchical likelihood-ratio test (GTR with gamma distributed rates approximated by four rate categories, $\left.\alpha=0.756, p_{\text {invar }}=0.306, \mathrm{R}_{(\mathrm{AC})}=8.00, \mathrm{R}_{(\mathrm{AG})}=12.05, \mathrm{R}_{(\mathrm{AT})}=3.79, \mathrm{R}_{(\mathrm{CG})}=1.75, \mathrm{R}_{(\mathrm{CT})}=47.65\right)$. Maximum-parsimony analysis produced two very similar shortest trees, a strict consensus of which is shown in Fig. 6 . Note that in the MP analysis the genus Cuspidoserol is is monophyletic (bootstrap 83 and 62, Bremer support 3 and 4 in schemes TV1 and TV2).

therein). The serolid isopods exceed the longest crustacean sequence for the fragment used in this study (from the 5'-end of helix E23_1 to the 3'-end of helix E23_2) known until now (Daphnia pulex, Branchiopoda) by more than 270 nucleotides (Table 3).

Even though the helices E23 5 and the basal part of E23 1 can be tentatively identified by the presence of compensatory substitutions in stems, secondary structure is of little help in the task of achieving an unambiguously aligned dataset. There is no independently derived model of secondary structure for a crustacean nuclear small subunit ribosomal RNA harboring an extreme expansion as found in the serolids. Since RNA secondary structure in vivo is often modified by proteins, it often coincides only in part with predictions made on the basis of energy minimization criteria alone (see, e.g., figures in LSU rRNA structures database; Gutell et al., 1993). The large number of suboptimal foldings that need to be taken into account for a large expansion segment spanning hundreds of bases as in this case make energy minimization of little help when trying to decide between two or more equally likely alternative alignments.

The following $18 \mathrm{~S}$ sequences had to be excluded because the typical expansion was either largely absent or so strongly modified that it was impossible to align with the rest of the ingroup sequences over a wide range of alignment parameters: Glyptonotus, Antarcturus, Serolina, and Spinoserolis spp (Table 4). The remaining serolid $18 \mathrm{~S}$ sequences were rooted with Cristaserolis gaudichaudii on the basis of its basal position relative to the remaining ingroup species in the mitochondrial 16S tree (Fig. 3). Approximately 49 bases in variable region $\mathrm{V} 4$, which correspond to the distal part of the helix E23 1 in the remaining ingroup sequences, had to be excluded from the subsequent analyses.

Of the remaining 681 positions in the $18 \mathrm{~S}$ dataset, 285 are variable and 196 are parsimony informative. The sequence length varies between 659 and 665 included nucleotides with an average GC content of $55 \%$. None of the sequences in this dataset deviated significantly from the mean $(P>0.1)$.

The LRT suggests the use of the HKY model ( $\mathrm{Ha}$ segawa et al., 1985) with gamma-distributed rates for the 185 dataset. Figure 2 shows a linear increase of observed transitions and transversions with evolutionary distance between taxa, thus indicating the absence of marked saturation effects in the al igned nuclear SSU sequences. The ML tree of the nuclear 18S dataset (Fig. 4 ) is compatible with the tree derived from the mitochondrial $16 \mathrm{~S}$ gene, although their resolution differs. Particularly well-defined splits include the two South American vs Antarctic species and the split within the Antarctic species between the genus Ceratoserolis and the group I. Within group I there is also support for a group consisting of Cuspidoserolis spp., Acutiserolis, and Serolella. An MP analysis yields a very similar tree, the only difference between them being that Septemserolis branches off first in group I, although support for this node is low (Bremer support 0; bootstrap support 61 and $55 \%$ in weighting schemes TV1 and TV2, respectively). 
TABLE 4

\section{Genetic Distances in Pairwise Sequence Comparisons for Mitochondrial LSU rR NA Gene (GTR Model; Lower Triangle) and Nuclear SSU rRNA Gene (HKY Model; Upper Triangle)}

\begin{tabular}{|c|c|c|c|c|c|c|c|c|}
\hline & 1 & 2 & 3 & 4 & 5 & 6 & 7 & 8 \\
\hline 1 Glyptonotus antarcticus & $*$ & 3.30413675 & 14.7152062 & 14.3595142 & 13.8306503 & 10.6471748 & 11.9074402 & 12.2802076 \\
\hline 2 Plakarthrium/ Antarcturus & 0.90078294 & $*$ & 6.14623404 & 6.98337555 & 5.69588372 & 5.35654736 & 5.61915493 & 5.7375885 \\
\hline 3 Ceratoserolis trilobitoides & 0.75980914 & 1.10906732 & $*$ & 0.00153428 & 0.00645003 & 0.17212565 & 0.17168441 & 0.18234748 \\
\hline 4 Ceratoserolis meridionalis & 0.72739416 & 1.5617342 & 0.13472591 & $*$ & 0.00808763 & 0.17244168 & 0.17199968 & 0.182668 \\
\hline 5 Ceratoserolis pasternaki & 0.76908267 & 1.4356879 & 0.16626225 & 0.14760877 & $*$ & 0.18998972 & 0.18921052 & 0.20049295 \\
\hline 6 Cuspidoserolis Iuethje & 0.88152319 & 1.22432709 & 0.55514109 & 0.34533557 & 0.39720196 & $*$ & 0.00307788 & 0.00966094 \\
\hline 7 Cuspidoserol is johnstoni & 0.72296554 & 1.09742415 & 0.45905897 & 0.41679555 & 0.31001285 & 0.08449046 & $*$ & 0.00971693 \\
\hline 8 Serolella bouvieri & 0.69500041 & 1.25176597 & 0.41233584 & 0.48262221 & 0.3805766 & 0.13778922 & 0.13252535 & $*$ \\
\hline 9 Acutiserolis bromleyana & 0.702636 & 1.07299316 & 0.51990461 & & 0.37874 & 0.0958487 & 0.109 & 0.08288705 \\
\hline 10 Septemserolis glacial is & 0.64116013 & 1.053617 & 0.37824339 & 0.38709545 & 0.29524353 & 0.16813637 & 0.14821562 & 0.11735931 \\
\hline 11 Frontoserol is waegele & 0.61191791 & 0.8428942 & 0.34523389 & 0.37572241 & 0.26931065 & 0.24903575 & 0.17921206 & 0.15290785 \\
\hline 12 Paraserolis polita & 0.78822678 & 1.07715642 & 0.60525805 & 0.39911902 & 0.38090894 & 0.34488508 & 0.25910783 & 0.27777246 \\
\hline 13 Spinoserolislatifrons & 0.75863814 & 1.12550855 & 0.32463613 & 0.33357707 & 0.34456381 & 0.48933521 & 0.3405754 & 0.33644694 \\
\hline 14 Spinoserolis beddardi & 0.60400558 & 1.02502811 & 0.29843563 & 0.32273975 & 0.308945 & 0.45665255 & 0.40378579 & 0.32004032 \\
\hline 15 Serolis paradoxa & 0.8453325 & 0.90889305 & 0.46356979 & 0.40592912 & 0.33668345 & 0.61509538 & 0.55199188 & 0.43332431 \\
\hline 16 Cristaserolis gaudichaudii & 0.84553593 & 1.28733444 & 0.54062855 & 0.64626664 & 0.51356733 & 1.12604702 & 0.81497353 & 0.59307468 \\
\hline 17 Serolina bakeri & 0.9190675 & 1.13853145 & 0.70040274 & 0.71307182 & 0.67194992 & 0.88266587 & 0.89475292 & 0.76841342 \\
\hline
\end{tabular}

Note. Distances were cal culated using gamma distributed rates with values for shape parameters al pha and proportion of invariable sites as used for constructing trees for the respective datasets (see text). Nuclear 18 S sequences of species 1, 2, 13, 14, and 17 were excluded from the analysis because of alignment difficulties (upper triangle, italics).

\section{Phylogenetic Analysis of Combined Nuclear and Mitochondrial Datasets}

For this purpose the $16 \mathrm{~S}$ dataset had to be reduced to the same taxa for which 185 data are available. The incongruence length difference test does not provide evidence for incompatible phylogenetic signal in the data partitions between the two genes for the pruned dataset ( $P=0.639$ ILD; branch-and-bound, 1000 replicates). Combining the datasets for the mitochondrial $16 \mathrm{~S}$ and the nuclear 18S genes yields 1124 aligned nucleotide positions of which 448 are variable and 213 parsimony informative (i.e., shared by two or more taxa). For the combined data of the remaining 12 species, themodel test identifies the general timereversible model with gamma-distributed rates and consideration of invariable sites as best suited for tree construction under the $\mathrm{ML}$ criterion.

The ML tree of the combined data is well resolved (Fig. 5). It shows essentially the same groups as were identified in the separate datasets, although the puzzling support values are, on average, higher in the tree based on the combined data.

An analysis of the combined datamatrix under maximum-parsimony criterion yields a single, fully resolved shortest tree which is shown in the right half of Fig. 5 (574 steps, $\mathrm{Cl}=0.708, \mathrm{RI}=0.648, \mathrm{RC}=0.456$ ). Downweighting transitions by a factor of two or three (schemes TV2 and TV3) leaves this topology unchanged, indicating a robust phylogenetic signal in the data.

Similar to thesituation in the ML tree, bootstrapping the MP tree indicates that, even though the topology shown in Fig. 5 is preferred, the available data cannot fully exclude the possibility that a monophyletic (Frontoserolis, Paraserolis) may be the sister group to the rest of group I and a monophyletic (Serolella, Acutiserolis) may be the sister to the genus Cuspidoserol is.

\section{Monophyly of Cuspidoserol is: Maximum-Likelihood versus Maximum-Parsimony}

As Brandt (1988) convincingly argued, monophyly of the newly recognized genus Cuspidoserolis is morphologically the strongly preferred option. This view is corroborated by maximum-parsimony methods, which consistently group the two Cuspidoserolis species in this study into one well-supported monophyletic taxon (16S and 16S and 18S combined), yet maximumlikelihood methods tend to recognize the paraphyly of the genus, even though this evidence is rather weak in the combined dataset (Fig. 5, left).

The shortest tree containing a paraphyletic Cuspidoserolis is 6 steps longer than the shortest tree without constraints which recognize the monophyly of the genus (580 vs 574 steps for all species in Fig. 5 or 213 vs 219 steps for species in group I alone). In the combined datamatrix there are eight positions supporting the monophyly of Cuspidoserolis but only a single position supporting the topology favored by the $\mathrm{ML}$ analysis. This situation is stable over a wide range of parameters permitting up to $45 \%$ noise in the outgroup. 
TABLE 4-Continued

\begin{tabular}{|c|c|c|c|c|c|c|c|c|}
\hline 9 & 10 & 11 & 12 & 13 & 14 & 15 & 16 & 17 \\
\hline 10.8995655 & 10.8873739 & 10.8591765 & 11.3813267 & 3467.93 & 314.666 & 12.6948814 & 8.31737614 & 550.212 \\
\hline 5.32922459 & 5.88648319 & 5.35651016 & 5.68616009 & 6935.87 & 38.175312 & 5.22110271 & 5.289985357 & 36.885387 \\
\hline 0.17163825 & 0.16159771 & 0.157440066 & 0.20336965 & 899.998 & 108.373 & 0.20374218 & 0.39383179 & 107.953 \\
\hline 0.17197739 & 0.16187334 & 0.15771325 & 0.19276258 & 906.673 & 107.786 & 0.19891524 & 0.39491528 & 110.183 \\
\hline 0.18916198 & 0.17826034 & 0.17439346 & 0.224949859 & 898.037 & 108.248 & 0.23467578 & 0.43762794 & 107.179 \\
\hline 0.00308263 & 0.02057778 & 0.0131965 & 0.0352237 & 292.564 & 54.5140038 & 0.13265078 & 0.28596315 & 110.051 \\
\hline 0.00309239 & 0.02050214 & 0.01310495 & 0.03984421 & 311.125 & 56.6472244 & 0.13662355 & 0.28293267 & 118.596 \\
\hline 0.00973227 & 0.02442037 & 0.01672151 & 0.0444871 & 254.49 & 49.7058525 & 0.13680431 & 0.31246653 & 127.484 \\
\hline$*$ & 0.02049657 & 0.1311747 & 0.03981629 & 313.576 & 57.0868607 & 0.13665777 & 0.28277612 & 127.041 \\
\hline 0.15185043 & * & 0.02050598 & 0.04692317 & 299.001 & 51.7074509 & 0.14405501 & 0.30100667 & 101.424 \\
\hline 0.17588584 & 0.17050368 & $*$ & 0.03504891 & 299.297 & 55.6314125 & 0.15642296 & 0.30790198 & 116.453 \\
\hline 0.2643927 & 0.28859192 & 0.21150476 & $*$ & 284.233 & 53.5266953 & 0.19015117 & 0.30593759 & 122.827 \\
\hline 0.3497498 & 0.38949189 & 0.32047501 & 0.43677524 & $*$ & 0.00504084 & 441.907 & 132.38 & 6935.87 \\
\hline 0.33737868 & 0.35381511 & 0.25610024 & 0.44639888 & 0.07132339 & $*$ & 63.5655098 & 110.763 & 6935.87 \\
\hline 0.47434729 & 0.37708876 & 0.28162026 & 0.41996697 & 0.62233877 & 0.5127669 & $*$ & 0.22291665 & 108.483 \\
\hline 0.77567106 & 0.63169569 & 0.42826229 & 0.57179363 & 0.56758422 & 0.47109738 & 0.56714034 & $*$ & 103.457 \\
\hline 0.84383118 & 0.89950794 & 0.61409116 & 0.91712201 & 0.7943787 & 0.64971763 & 0.9664005 & 0.82898688 & $*$ \\
\hline
\end{tabular}

On the basis of this evidence and in view of the fact that a tree containing a monophyletic genus Cuspidose rol is is statistically not significantly more unlikely than the ML tree under maximum-likelihood criterion (Kishino-Hasegawa test, $\mathrm{P}>0.2$ ), it may be concluded that the MP topology with Cuspidoserolis monophyletic (Fig. 5, right half) more likely reflects the true phylogenetic history of the species in group I.

For the remainder of the species, both genes result in a congruent topology, as shown in Fig. 5, according to which the nodes that are incongruently resolved, depending on the method of analysis, are among the most recent bifurcations in the tree. The rather weak influence of saturation effects, at least for the younger nodes (Fig. 2), makes it unlikely that homoplasies due to multiple hits account for the difficulties of the ML method in resolving relationships in group I. More likely, the small genetic distance between Acutiserolis, Cuspidoserolis, and Serolela (Table 4), indicating a short time interval between speciation events, is responsible for the difficulties of the ML reconstruction. The relatively young age of the nodes under question may account for the relatively better performance of maximum-parsimony here.

\section{DISCUSSION}

\section{Phyl ogenetic Analysis of Nuclear and Mitochondrial rRNA Sequences and Usefulness of the LRT Test}

The phylogenetic analysis of the nuclear small subunit rRNA and the mitochondrial large subunit rRNA gene fragments of serolid isopods is consistent with the idea that, despite their independent modes of inheritance, both genes share a common phylogenetic history. This finding increases the likelihood that the molecular data actually reflect the phylogenetic history of the species under study. Both data partitions yield congruent results, although the occurrence of unalignable V4 sequences led to the exclusion of three ingroup species from the nSSU and combined datasets.

Likelihood-ratio tests have become a useful tool in various fields, one being the choice of sequence evolution models in molecular phylogenetics (Huelsenbeck and Crandall, 1997; Huelsenbeck and Rannala, 1997). The hierarchical procedure from simpler to more complex models of sequence evolution applied with the likelihood-ratio test does not per se guarantee that the model that is finally chosen provides an optimal description of the underlying evolutionary processes (Swofford et al., 1996). In principle, even in the complete absence of an adequate model, the LRT would identify a preferred model by exclusion of models with relatively worse fit of the applied test statistic. Nevertheless, the LRT makes this critical step in phylogenetic analysis (model selection) objectively justifiable and helps to avoid the circularity of tree construction that would occur if the choice of the model was based on resolution or (desired) topology of the resulting tree.

\section{Taxonomic I mplications of the Mol ecular Data}

The molecular data yield a robust phylogeny which can be supported by morphol ogical arguments. Some of the nodes agree with one of the morphological hypotheses or represent one possible solution for previously unresolved relationships (Figs. 1 and 6). Although a detailed analysis of morphological characters is not intended at this stage, some of the most evident implications from the molecular data shall be discussed here. Frontoserolis as defined by Brandt (1991) originally contained 12 species, 4 of which (Frontoserolis 


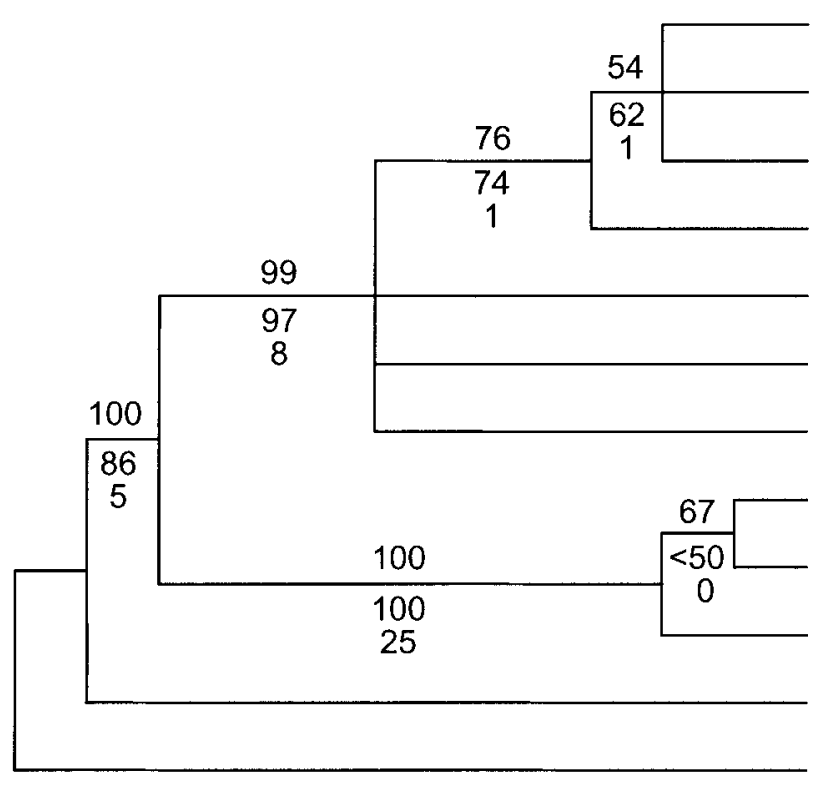

Cuspidoserolis johnstoni

Cuspidoserolis luethjei

Acutiserolis bromleyana

Serolella bouvieri

Septemserolis glacialis

Paraserolis polita

Frontoserolis waegelei

Ceratoserolis trilobitoides

Ceratoserolis pasternaki

Ceratoserolis meridionalis

Serolis paradoxa

Cristaserolis gaudichaudii

FIG. 4. Maximum-likelihood tree based on the V4 region of the nuclear small subunit rRNA gene (18S) of 12 species of serolid isopods (Puzzle 4.02; puzzling support values above branches, 1000 replicates). The choice of the model of sequence evolution is based on a hierarchical likelihood-ratio test (HKY85 Model, gamma-distributed rates approximated by eight rate categories, $\alpha=0.18$, ti/tv $=1.024$ ). Below the branches are the values for bootstrap support for the nodes in MP analysis (upper figure; scheme TV1, 1000 replicates, random addition of sequences, heuristic search) and for Bremer support (lower figure). This tree is rooted with Cristaserolis based on its basal position in the 16S tree (Fig. 3) with respect to the species included here.

waegelei, Serolela bouvieri, Paraserolis polita, and Septemserolis glacialis) are included in this study (see also Brandt, 1993). Examining a large collection of new material, Wägele (1994) discovered sexual dimorphism of pereiopod 7 in Cuspidoserol is and in a subset of the species in Frontoserol iss. I. and reorganized the phylogeny accordingly. Frontoserolis s. str. was reduced to 3 species and the other species were transferred to other genera to make the phylogeny consistent with the occurrence of the newly scored characters (Fig. 1). This study provides independent evidence from two genes that recognition of Cuspidoserolis Brandt, 1988 and Acutiserolis Brandt, 1988 indeed require splitting of Frontoserolis sensu lato, which would otherwise become paraphyletic (Figs. 3-6).

With the exception of Acutiserolis, all nodes in group I (see Fig. 5) are fully resolved and receive good support. The molecular data favor a sister group relationship between Acutiserol is and Cuspidoserolis, although the bootstrap and puzzling support values are
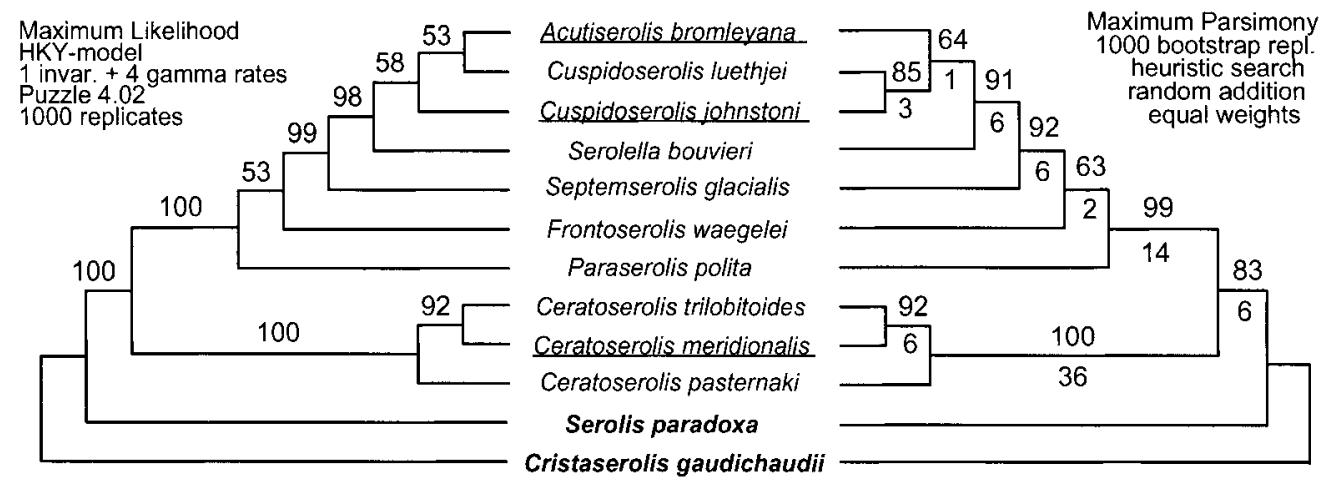

FIG. 5. Phylogenetic tree of serolid isopods based on combined mitochondrial and nuclear rRNA gene datasets (16S and 18S). For the maximum-likelihood analysis, the HKY 85 model with invariable sites and gamma-distributed rates approximated by four rate categories was chosen by the LRT; sequence evolution parameters were estimated within Puzzle $4.02\left(\alpha=0.19, \mathrm{ti} / \mathrm{tv}=1.61, \mathrm{p}_{\text {invar }}=0\right)$ with the number of replications set to 1000 quartet puzzling steps. For the MP tree, bootstrap values of 1000 replicates with random addition of taxa are shown above the branches, with equal weighting and Bremer support shown bel ow. Alignment gaps were treated as missing information in MP trees; positions containing gaps were ignored in $\mathrm{ML}$ analysis. 


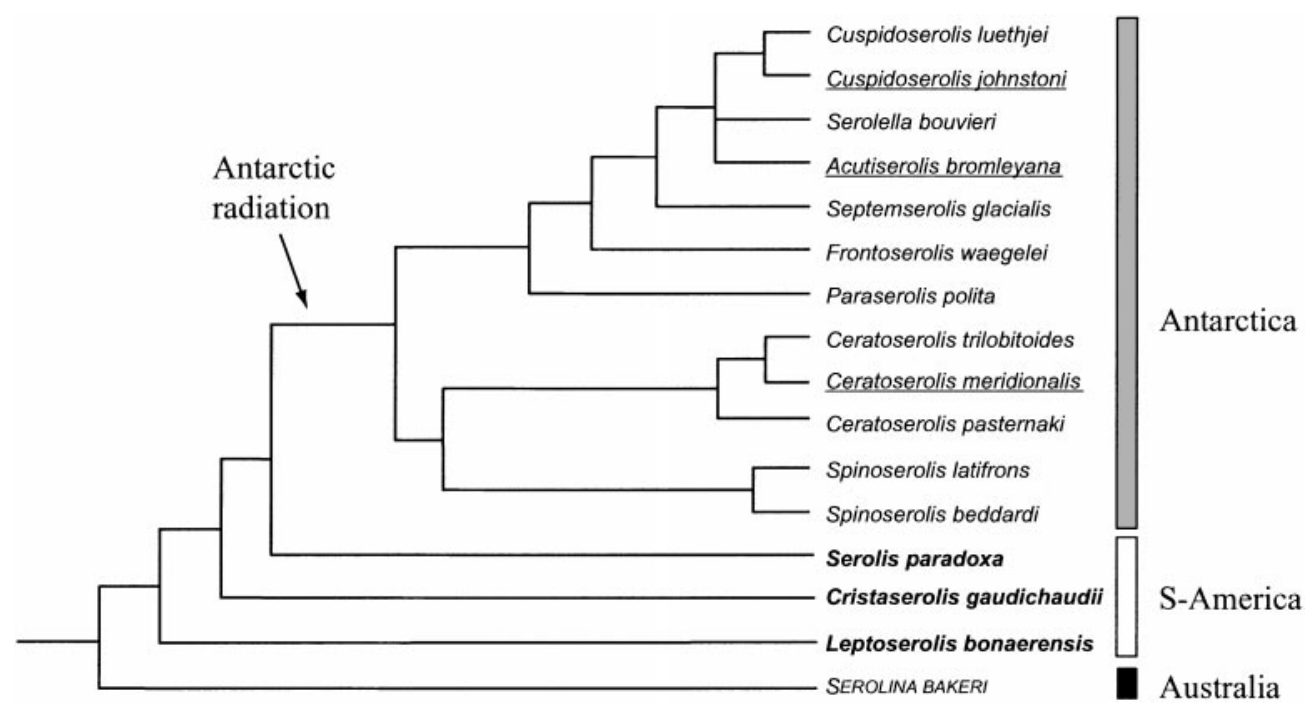

FIG. 6. Patterns of horizontal and vertical distribution of 16 species of serolid isopods. The tree represents the current best estimate of the phylogeny of this group and is based on the MP tree of the combined 16S and 18S datasets. Serolina bakeri, Leptoserolis bonaerensis, and Spinoserol is spp. have been included on the basis of their position in the 16S rRNA tree, the branches resolving the positions of Serolella and Acutiserol is have been collapsed due to ambiguous phylogenetic signal in the data (see text for details). This topology is identical to the strict consensus of the two shortest 16S trees. Underscored species names indicate occurrence in the deep sea; all other species live in shallower waters.

relatively low (Figs. 5 and 6). This is in congruence with morphology. The mediocaudal lobe or spine of the cephalothorax is a potential synapomorphy of this group (Brandt, 1991), but it is only weakly expressed in Acutiserolis and analogous structures occur outside this group (Serol ina, Heteroserol is; see Wägele, 1994).

The molecular data provide solid support for a monophylum consisting of Cuspidoserol is, Serolella, Septemserolis, and Acutiserolis. For the first three genera, a sexually dimorphic pereiopod 7 is known (Wägele, 1994). This, however, is also visible in the Acutiserol is material from the Drake Passage (this study) and in the drawings of Poore and Brandt (1997). A sexually dimorphic pereiopod 7 therefore forms a potential morphological synapomorphy and supports the molecular phylogeny.

One of the most striking discrepancies between the two morphological hypotheses (Fig. 1) and between the molecular and the morphol ogical data (Figs. 1, 5, and 6) is the position of Acutiserolis bromleyana and Serol is paradoxa. Wägele (1994) placed these species close together, based mainly on the bilobed shape of the endopod of the 4th pleopod (PIp4). The shortest tree that contains this group is 612 steps long, as opposed to 574 steps for the unconstrained tree. The molecular data strongly suggest that this is a polyphyletic grouping and support an alternative position instead: Acutiserol is groups together with Cuspi doserol is (see Brandt, 1991), whereas Serol is paradoxa occupies a more basal position (Figs. 4 and 5). This hypothesis, which is strongly supported by both mitochondrial and nuclear genes independently, casts doubts on the phylogenetic usefulness of the shape of PIp4. These doubts are further corroborated by the fact that neither Acutiserolis material from the Coral Sea (Poore and Brandt, 1997) nor from the Drake Passage (this study) had a bilobed PIp4. Beddard (1884), however, mentions this feature in his text (p. 60) and provides a drawing (PI. V, Fig. 11) in which an apical division of the endopod of PIp4 is clearly visible. It must be concluded either that not all species that are currently assigned to Acutiserolis express that feature or that there is an extensive amount of intraspecific morphological variation. The shape of the 4th pleopod as currently scored should therefore not be treated as a reliable synapomorphy for phylogenetic purposes. As a consequence, it seems logical to reestablish Acutiserolis Brandt, 1988 as a valid genus (see Poore and Brandt, 1997) and not as a subgenus of Serol is Leach, 1818, as proposed by Wägele (1994). Whether this also applies to Acanthoserolis Brandt, 1988, which was also reduced to a subgenus of Serol is s. str., remains to be seen when further material becomes available for molecular analysis.

\section{Patterns of Horizontal and Vertical Distribution}

The molecular phylogeny presented in this study allows a meaningful interpretation of species distribution of extant serolid isopods. Even though the results of this study should not be overgeneralized in view of the fact that a large number of taxa, especially from outside the Southern Ocean, have not been included, some pattern emerges from the molecular phylogeny.

Previously, there was no evidence for a clean biogeographic split in distribution patterns (Fig. 1). Brandt 
(1991) and Wägele (1994) agree that the distribution pattern of the extant serolid fauna is partly the result of continental drift vicariance (e.g., Serolina in Australia), which became further modified by colonization, dispersal, and palaeoclimatic events. Both reconstructions lead to phylograms in which at least the taxa with South American and Antarctic distribution are distributed over the tree, even when only the species covered in this study are considered. The lack of a clear biogeographic pattern leads the authors to conclude that the main radiation of serolids must have taken place long before the separation of South America and Antarctica (Crame, 1997). The existence of a large monophyletic group of Southern Ocean serolid species in the molecular phylogeny is an intriguing finding.

The paraphyly of the three South American species with respect to the Antarctic species group and the well-supported monophyly of the Antarctic species in this study are presumably not independent of the geological events in this area. Two scenarios are possible: either the Serolidae colonized Antarctic waters only once, presumably from the South American shelf, and radiated after the Drake Passage provided some isolation from the South American continent or the extant Antarctic serolids arethe survivors of the serolid fauna which inhabited Gondwana before the supercontinent disintegrated. In the latter case, however, we need to make additional assumptions to explain why there are no Antarctic species today that are most closely related to South American species. In the absence of an explanation for differential survival of species, the hypothesis of a radiation of the Serolidae in Antarctic waters after the opening of the Drake Passage is preferred. It remains to be seen whether this applies to all species of the Serolidae that today live in Antarctic waters when more material becomes available for molecular analysis. This is especially true of the area on both sides of the Drake Passage. The isolation is historically younger there than the separation of Antarctica and Australia and biogeographically less effective due to the presence of the Scotia Arc (Winkler, 1994).

According to the molecular phylogeny, all three deepsea species in this study originate from within the Antarctic radiation of shallow-water serolids. Thethree cases of polar submergence appear not to be phylogenetically linked, however.

Acutiserolis is a deep-sea taxon that, according to morphological data, evolved independently from the blind deep-sea genera Glabroserol is, Caecoserolis, and Atl antoserolis (Wägele, 1994). The new molecular data suggest an origin from Antarctic shelf-dwelling serolids (Figs. 5 and 6). A number of other shelf genera al so have representatives in the deep sea (Cuspidoserolis johnstoni and Ceratoserolis meridionalis) which have at least partially reduced functional eyes and prol onged coxal plates compared to their sibling species on the
Antarctic shelf (Cuspidoserolis luethje and Ceratoserolis tril obitoides; see F ig. 6). Although the depth range of the pairs of sibling species overlaps across their whole distribution range, they seem to occupy different water depths in the same area (pers. observ.). However, neither of these deep-sea species is as specialized to life in the deep sea as the presumably older blind deep-sea genera mentioned above. The last common ancestor of the deep-sea species Cuspidoser ol is johnstoni and Actuserolis is unlikely to have lived in the deep sea, since the sibling species $C$. Iuethjei occurs exclusively on the Antarctic shelf today and possesses no adaptations to life in deep-sea environments. The serolids of the Antarctic shelf must therefore have colonized the deep sea three times independently during the relatively recent evolution of serolids. This finding agrees well with previous work based on morphological data according to which the Serolidae are a recent addition to the deep-sea fauna (Brandt, 1991, 1992; Wilson, 1998). Among other taxa, a close relationship between deepsea and Antarctic fauna has also been found with examples of polar emergence as well as polar submergence (Barthel and Tendal, 1994; Brandt, 1991; Brey et al., 1996).

All other deep-sea serolids (Caecoserol is, Atlantoserolis, and Glabroserolis) form a monophyletic group, according to Wägele (1994), which is presumably more closely related to South American shallow-water genera (Cristaserolis, Brazilserolis, and Leptoserolis) than to any of the deep-water species covered in this study. This group might therefore contain the predecessors of a single colonization event of the deep sea that originated from the South American shelf and is probably unrelated to the multiple cases of invasions into the deep sea that occurred from theAntarctic shelf.

If true, this pattern is in accordance with the idea that temperate or tropical shelf ecosystems are more strongly isolated from the deep sea than polar shelf systems. The cooling of the Southern Ocean since the mid-E ocene and the suppression of the Antarctic shelf down to 500-600 m water depth have created environmental conditions that are similar to those of the deep sea, thus facilitating a transition between these two ecosystems (Clarke and Crame, 1992).

\section{Phylogenetic Utility of Ribosomal Expansion Segments}

While at higher taxonomic levels the expansion segments are in many cases too variable and are usually discarded from the analysis (Giribet et al., 1996), they turn out to be informative at the family level in serolid isopods. Their use, however, is associated with problems.

The extraordinarily high distance values for the excluded nuclear $18 \mathrm{~S}$ sequences in Table 4 clearly result from inclusion of large stretches of unalignable nucleotides in the outgroup and three ingroup species. A more detailed account of the properties and evolution 
of this part of the $\mathrm{V} 4$ expansion segment is in preparation (Held and Dreyer, in prep.), but some points which are directly relevant to phylogenetic inference shall be briefly presented here. For some difficult to align sequences in this study (Glyptonotus) it cannot be excluded on the basis of the presented data that they are simply too distant from the ingroup and hence largely saturated. The difference in length of more than 200 nucleotides between most ingroup sequences and Antarcturus in the outgroup, however, suggests that, in addition to inheritance of single-site substitutions, largescaleinsertion/deletion events also play an important role in sequence evolution of this gene fragment (Table 2).

This raises doubt concerning the homology of entire regions of nucleotides, even among sequences of similar length. For branchiopod crustaceans, insertion of noncontiguous blocks of nucl eotides in different parts of the V4 and V7 regions could be shown (Crease and Taylor, 1998). Acquisition of entire new helices within these gene regions has been found in branchiopod crustacea and in tiger beetles (Vogler and Pearson, 1996). A similar mechanism might be responsible for the occurrence of the three distinctly divergent ingroup sequences (Table 4). The novel types of V4 expansion segments in Spinoserolis spp. and Serolina ("Iongbranch" species) must have evolved within the serolids themselves, as the outgroup comparison shows. They have to be regarded as autapomorphies of the branches leading to Spinoserol is and Serolina because the similarities between outgroup and short-branch serolids are much too complex to be explained by convergence (data not shown). It has to be concluded that the substitution process in these three species differs from that of the rest of the species for unknown reasons. Without a better understanding of why and in which way these sequences have evolved differently, these sequences cannot be used to reconstruct a reliable and historically correct phylogeny. The congruence of the results of 165 and 185 of the included species indicates that in the remaining sequences there was a signal that most likely reflects the phylogenetic history of the species. The danger of interpreting a less dramatically aberrant sequence type as phylogenetic signal, however, speaks against the routine use of the nuclear V4 expansion segment in routine studies of molecular phylogeny, especially if only a single gene is used.

\section{ACKNOWLEDG MENTS}

This paper has greatly benefited from the helpful criticism of two anonymous reviewers. Thanks are also due to J.-W. Wägele, C. D. Schubart, and A. Brandt for hel pful discussion and advice. H. Dreyer kindly provided advice and some of the primers used for the 18S expansion segment and C. Epplen provided the modified DTAB/ CTAB extraction protocol. J. Kowalke, G. Duhamel, and G. Poore collected additional isopod material. A number of participants of the cruises ANT XIII/3 and ANT XIV/2 hel ped during sorting of the catch on deck, in particular L. Allcock, S. Steimer, and S. Krey, who also assisted during processing of the probes on board. C. de Broyer, G. Chapelle, and C. O. Coleman collaborated in deploying fishery gear. Thanks are also due to captains, chief scientists, and crew members of the two "Polarstern"-cruises. C. Rios, E. Mutschke, E. Morrison, and J. Ramirez provided logistic support and diving equipment in Punta Arenas. Without their kind help, scuba diving in the Magellan Strait would not have been possible. This project was supported by a grant to J .-W. Wägele from the Deutsche Forschungsgemeinschaft (Wa 530/16).

\section{REFERENCES}

Barthel, D., and Tendal, O. S. (1994). “Antarctic Hexactinellida," 6, Koeltz Scientific Books, Koenigstein.

Beddard, F. E. (1884). Report on the I sopoda collected by the H. M. S. Challenger during the years 1873-1876. Part I. The genus Serol is. Challenger Rep. Zool. 11: 1-85.

Brandt, A. (1988). Antarctic Serolidae and Cirolanidae (Crustacea: I sopoda): New genera, new species and redescriptions. In "Theses Zoologicae" (R. Fricke, Ed.), Vol. 10, Koeltz Scientific Books, Koenigstein.

Brandt, A. (1991). Colonization of the Antarctic shelf by the I sopoda (Crustacea, Malacostraca). BerichtePolarforschung 98: 1-240.

Brandt, A. (1992). Origin of Antarctic Isopoda (Crustacea, Malacostraca). Mar. Biol. 113: 415-423.

Brandt, A. (1993). Comparative morphology of Frontoserol is Brandt, 1991, Heteroserol is Brandt, 1991, and Thysanoserol is Brandt, 1991 (Crustacea, I sopoda, Serolidae). Zool . Anzeiger 229: 227-235.

Brey, T., Dahm, C., Gorny, M., et al. (1996). Do Antarctic benthic invertebrates show an extended level of eurybathy? Antarctic Sci. 8: 3-6.

Clarke, A., and Crame, J. A. (1992). The Southern Ocean benthic fauna and climate change: A historical perspective. Philos. Trans. R. Soc. London B Biol. Sci. 338: 299-309.

Crame, J . A. (1997). An evolutionary framework for the polar regions. J . Biogeogr. 24: 1-9.

Crease, T. J., and Colbourne, J. K. (1998). The unusually long small-subunit ribosomal RNA of the crustacean Daphnia pulex: Sequence and predicted secondary structure. J. Mol. Evol. 46: 307-313.

Crease, T. J ., and Taylor, D. J . (1998). The origin and evolution of variable-region helices in V4 and V7 of the small-subunit ribosomal RNA of branchiopod crustaceans. Mol. Biol. Evol. 15: 1430-1446.

Cunningham, C. W. (1997). Can three incongruence tests predict when data should be combined? Mol. Biol. Evol. 14: 733-740.

Eriksson, T. (1998). AutoDecay (Version 4.0). Department of Botany, Stockholm Univ., Stockholm (computer program distributed by the author).

Farris, J. S., Källersjö, M., Kluge, A. G., et al. (1994). Testing significance of incongruence. Cladistics 10: 315-319.

Giribet, G., Carranza, S., Bagunà, J ., et al. (1996). First molecular evidence for the existence of a tardigrada + Arthropoda clade. Mol. Biol. Evol. 13: 76-84.

Gustincich, C., Manfioleti, G., Del Sal, G., et al. (1991). A fast method for high-quality genomic DNA extraction from whole human blood. BioTechniques 11: 298-302.

Gutell, R. R., Gray, M. W., and Schnare, M. N. (1993). A compilation of large subunit (23S and 23S-like) ribosomal RNA structures: 1993. Nucleic Acids Res. 21: 3055-3074.

Hancock, J. M., and Vogler, A. P. (1998). Modelling the structure of slippage-prone hypervariable RNA regions: The example of the tiger beetle 18S rRNA variable region V4. Nucleic Acids Res. 26: 1689-1699. 
Hasegawa, M., Kishino, H., and Yano, K. (1985). Dating of the human-ape splitting by a mol ecular clock of mitochondrial DNA. J . Mol. Evol. 22: 160-174.

Holdich, D. M., and Harrison, K. (1980). Morphological variation in the Serolis minuta-group (Isopoda: Serolidae) from Australian waters. Zool. J . Linnean Soc. 68: 373-386.

Huelsenbeck, J . P., and Crandall, K. A. (1997). Phylogeny estimation and hypothesis testing using maximum likelihood. Annu. Rev. Ecol. Syst. 28: 437-466.

Huelsenbeck, J. P., and Rannala, B. (1997). Phylogenetic methods come of age: Testing hypotheses in an evolutionary context. Science 276: 227-232.

Nicholas, K. B., and Nicholas, H. B. J . (1997). GeneDoc: A tool for editing and annotating multiple sequence alignments. Distributed by the author.

Palumbi, S. R., Martin, A., Romano, S., et al. (1991). "The Simple Fool's Guideto PCR: A Coll lection of PCR Protocols," Version 2, Univ. of Hawaii Press, Honolulu.

Poore, G. C. B., and Brandt, A. (1997). Crustacea I sopoda Serolidae: Acutiserolis cidaris and Caecoserolis novaecal edoniae, two new species from the Coral Sea. In "Résultats des Campagnes Musorstom" (A. Crosnier, Ed.), Vol. 18, pp. 151-168. Mém. Mus. Natn. Hist. Nat. 176, Paris.

Posada, D., and Crandall, K. A. (1998). Modeltest: Testing the model of DNA substitution. Bioinformatics 14: 817-818.

Schubart, C. D., Neigel, J . E., and Felder, D. L. (2000). The use of the mitochondrial 16S rRNA gene for phylogenetic and biogeographic studies of brachyuran Crustacea. Crustacean Issues, in press.

Schulenburg, J . H. G. v. d., Englisch, U., and Waegele, J .-W. (1999). Evolution of ITS1 rDNA in the Digenea (Plathyhel minthes: Trematoda): $3^{\prime}$ end sequence conservation and its phylogenetic utility. J . Mol. Evol. 48: 2-12.

Strimmer, K., and von Haeseler, A. (1996). Quartet puzzling: A quartet maximum likelihood method for reconstructing treetopologies. Mol. Biol. Evol. 13: 964-969.

Swofford, D. L. (1998). PAUP*. Phylogenetic analysis using parsi- mony (* and other methods) (Version 4.02 beta). Sinauer, Sunderland, MA.

Swofford, D. L., Olsen, G. J ., Waddell, P. J ., et al . (1996). Phylogenetic inference. In “Molecular Systematics” (D. M. Hillis, C. Moritz, and B. K. Mable, Eds.), 2nd ed., pp. 407-514. Sinauer, Sunderland, MA.

Thompson, J. D., Gibson, T. J ., Plewniak, F., et al. (1997). The ClustalX windows interface: Flexible strategies for multiple se quence alignment aided by quality analysis tools. Nucleic Acids Res. 24: 4876-4882.

Van de Peer, Y., Robbrecht, E., de Hoog, S., et al. (1999). Database on the structure of small subunit ribosomal RNA. Nucleic Acids Res. 27: 179-183.

Vogler, A. P., and Pearson, D. L. (1996). A molecular phylogeny of the tiger beetles (Cicindelidae): Congruence of mitochondrial and nuclear rDNA data sets. Mol. Phylogenet. Evol . 6: 321-338.

Wägele, J .-W. (1986). Polymorphism and distribution of Ceratoserol is tril obitoi des (Eights, 1833) (Crustacea, I sopoda) in the Weddell Sea and synonymy with C. cornuta (Studer, 1879). Polar Biol. 6: 127-137.

Wägele, J .-W. (1989). Evolution und phylogenetisches System der I sopoda. Stand der Forschung und neue Erkenntnisse. Zoologica 140: 1-262.

Wägele, J .-W. (1994). N otes on Antarctic and South American Serolidae (Crustacea, I sopoda) with remarks on the phylogenetic biogeography and a description of new genera. Zool. J ahrb. Abteilung Syst. Ökol. Geogr. Tiere 121: 3-69.

Wägele, J .-W. (1998). A priori estimation of phylogenetic information conserved in aligned sequences. Mol. Phylogenet. Evol . 9: 358-365.

Wilson, G. D. F. (1998). Historical influences on deep-sea isopod diversity in the Atlantic Ocean. In "Deep-Sea Biodiversity: A Compilation of Recent Advances in Honor of Robert R. Hessler" (C. R. Smith, L. S. Mullineaux, and A. Levin, Eds.), Vol. II, pp. 279-301. Pergamon, Oxford.

Winkler, H. (1994). Characterization of the Scotia Arc isopod fauna (Crustacea, Malacostraca) from a biogeographical point of view: A multivariate approach. BerichtePol arforschung 139: 1-196. 